\title{
The future of California raisins is drying on the vine
}

\author{
William L. Peacock \\ Frederick H. Swanson \\ $\nabla$
}

Scientists at the UC Kearney Research and Extension Center have developed a new method to produce dried-onvine (DOV) raisins. Prior DOV systems required costly trellising and harvesting equipment, putting DOV out of reach for most growers. Our new, within-row-alternate-bearing DOV (WRAB DOV) method can be used with the existing trellis and no retrofitting. DOV raisins are machine harvested, reducing human contact and production costs, and improving profitability. Drying raisins on the vine eliminates the need for intensive cultivation to prepare terraces down row middles. This method also removes the problem of using and disposing of paper trays, solving an important airquality issue for raisin growers.

$\mathrm{T}$ he California raisin industry consists of about 4,500 growers in the southern San Joaquin Valley, growing raisin grape varieties on 250,000 acres. Over $90 \%$ of the raisin crop is produced from the 'Thompson Seedless' variety. The 300,000 to 400,000 tons of raisins produced each year constitute about $40 \%$ of global production; in 2004, the raisin crop had a farm-gate value of one-third billion dollars.

The traditional method of handharvesting and drying grapes on trays for natural raisins has changed little over the past hundred years. Most hand-harvested raisin grapes are dried on individual paper trays placed on a smooth terrace prepared between vine rows. When drying is complete, the raisins are rolled up in the paper trays, then the rolls are picked up by hand or mechanically and the raisins are dumped into bulk containers for removal from the field. Paper trays are usually disposed of by burning in the field. This process

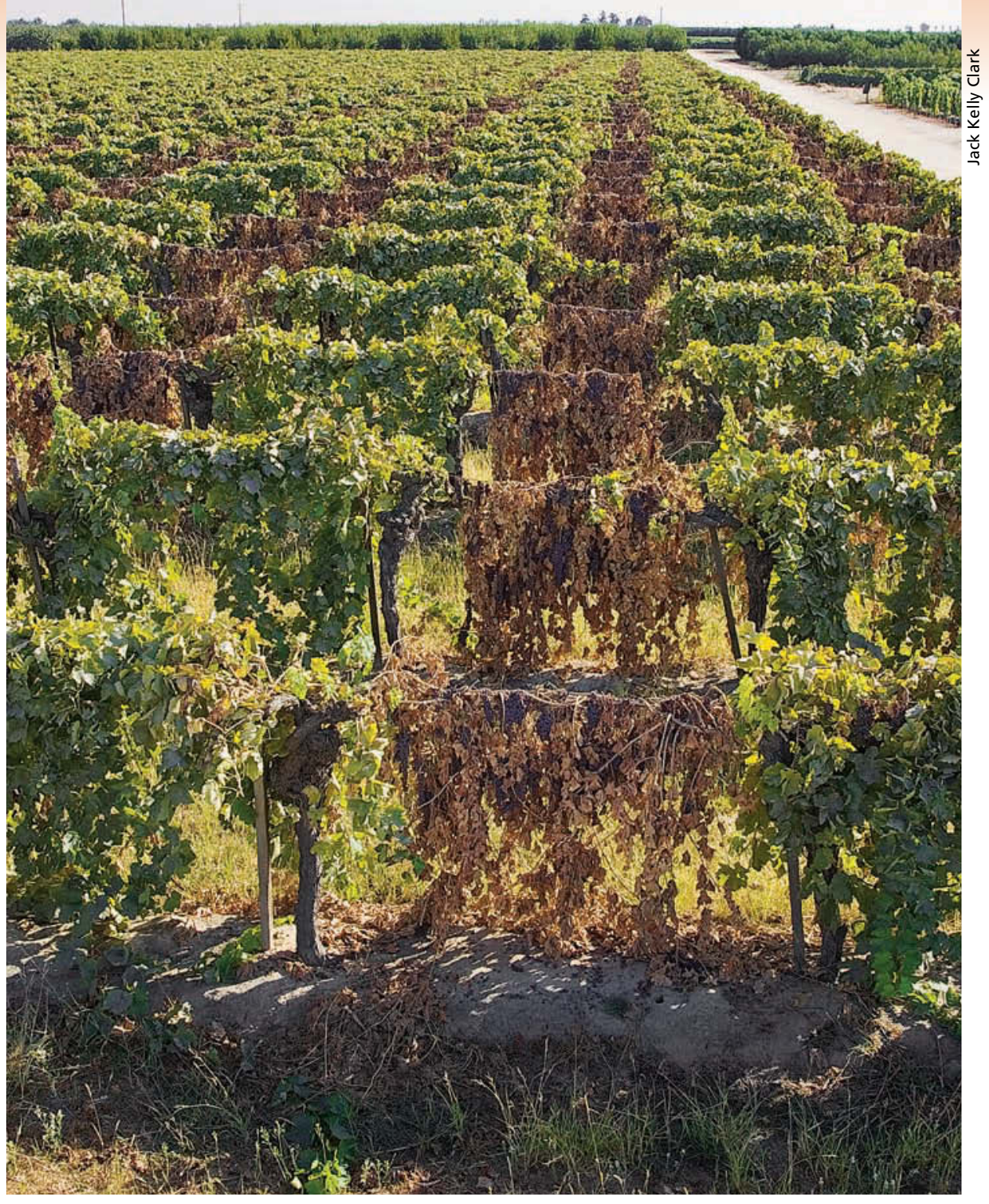

After more than a century of hand-harvesting and drying grapes on trays to produce raisins, California growers now have an economically viable alternative. The alternate bearing, dried-on-vine method (WRAB DOV) developed by Kearney scientists reduces production costs and can be used with existing trellises.

is labor intensive, requires close supervision and experienced management, and involves weather risks. In contrast, dried-on-vine (DOV) raisins are mechanically harvested, reducing the labor requirement. The cultivation required to prepare the terrace is eliminated, along with the problem of disposing of paper trays (Christensen and Peacock 2000).

DOV raisins have a milder flavor and no caramelization compared to traydried raisins. They are also rounder and have smaller wrinkles. This difference is the result of the drying environment. With tray-drying, the temperature on the tray surface can exceed ambient temperature by $30^{\circ} \mathrm{F}$ to $40^{\circ} \mathrm{F}$, and raisins dry in 10 to 20 days depending on the weather. In contrast, DOV raisins are dried on the vine at temperatures closer to ambient and it takes 30 to 40 days to complete the drying process.

The potential for drying raisins on the vine was first noted by scientists 
working at the UC Kearney Research and Extension Center (KREC) in 1965. Since then, a number of DOV systems have been developed by UC researchers and growers. These systems, however, require expensive trellising and harvesting equipment that excludes many growers from producing DOV raisins (Christensen 2000).

We developed a DOV raisin method at KREC that has opened the door for growers to produce DOV raisins. The method is based on the separation of fruiting canes and renewal shoots alternating between vine sections down the vineyard row. We call the method "within-row-alternate-bearing dried-on-vine" (WRAB DOV).

WRAB DOV is applicable to all raisin trellises, and raisins are harvested from the vine using a canopy shaker wine-grape harvester. Prior DOV systems, such as south side, overhead and open gable, required expensive trellising and harvesting equipment. Start-up costs were prohibitive for most growers, especially during the recent economic down cycle. However, the WRAB DOV method can be used with the existing trellis and no retrofitting.

Research began on the WRAB DOV method in 1999 at KREC. We compared WRAB DOV and traditional tray-drying, measuring yield, raisin quality and harvest costs over 4 consecutive years. Canopy management, summer pruning and harvesting techniques were developed for WRAB DOV. Various trellis widths were evaluated to determine the impact of trellis expansion on yield and vine capacity.

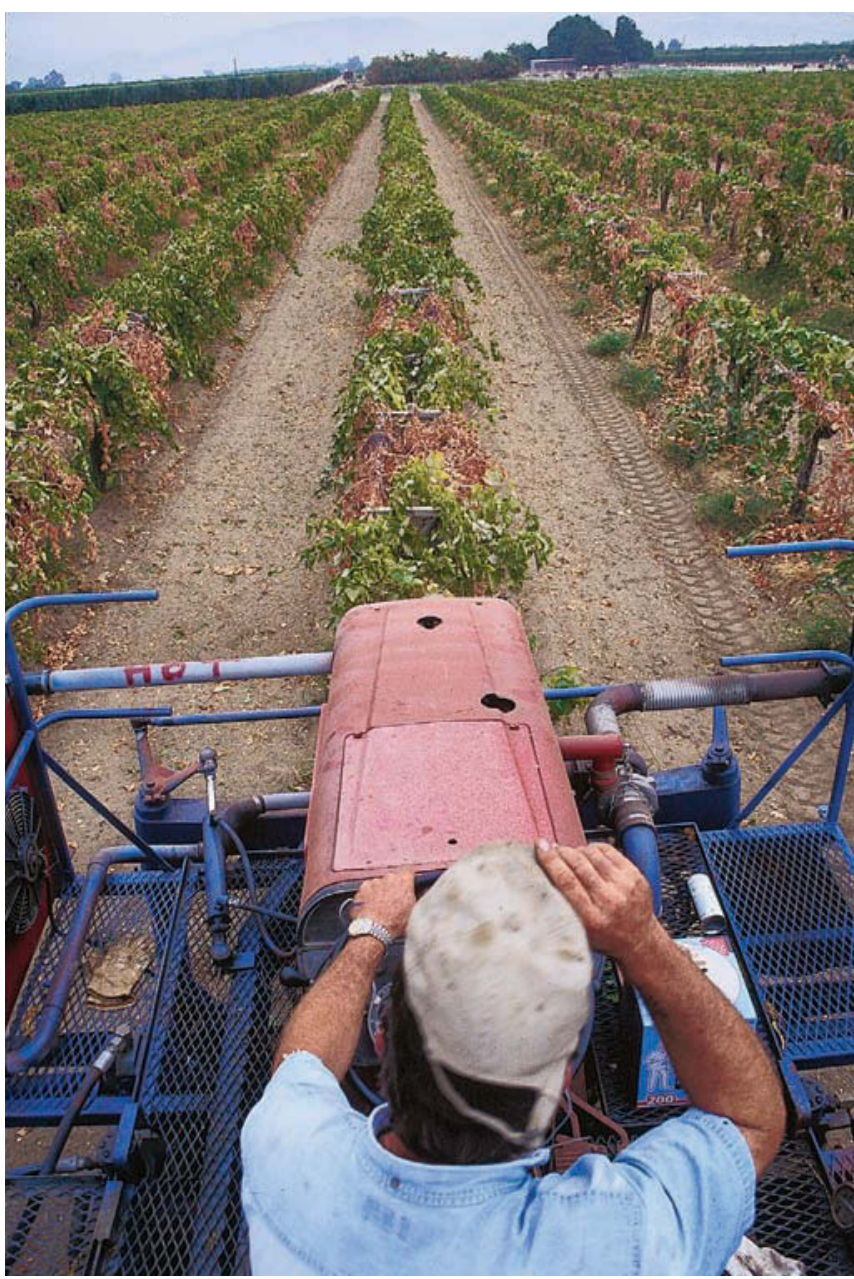

Above, dried-on-vine raisins can be mechanically harvested with a wine grape harvester. Below, hand-harvesting requires much higher costs for labor, paper tray disposal and preparation of clean middle rows.

\section{Production and canopy management}

We established a trial plot at KREC for the dual purposes of comparing WRAB DOV production with traditional tray-drying and evaluating various canopy-management techniques. It was located in a mature raisin block trellised with a cross-arm (18 inches and two wires) and 7-foot stakes. The experimental design was a completely randomized block with

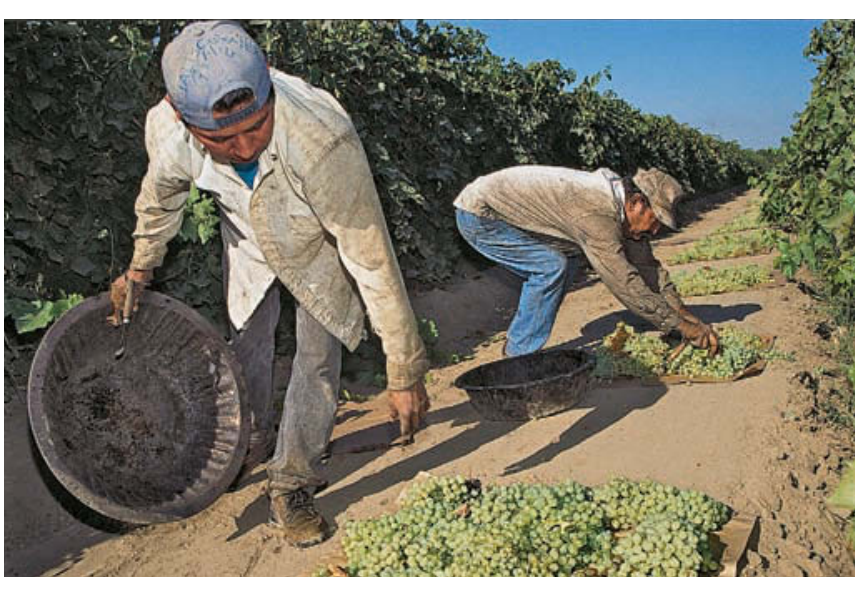

six blocks (replications) and four treatments, and using five vine plots. The three middle vines within the five vine plots were used for data collection. Treatments were WRAB DOV with: (1) no canopy management; (2) shoot thinning; (3) shoot thinning plus shoot positioning; and (4) control, traditional tray-drying. Statistical analysis was by ANOVA using least significant difference for treatment mean separation.

All DOV and tray-drying treatments were pruned to five fruiting canes and six renewal spurs. Fruiting canes were 12 to 15 nodes in length. Canes on the tray-drying treatments were tied in the traditional fashion, and canes on DOV were tied using the within-row alternate-bearing system.

Shoot thinning DOV treatments occurred in mid-April and consisted of retaining eight shoots on the renewal side of the vine to become the next year's fruiting canes. Shoots were selected based on their location. The goal was to establish a clear division between the renewal side and fruiting side of the head (trunk). Shoot positioning occurred in late May, around berry set, and consisted of wrapping or twirling five of the shoots that had been retained on the renewal side during the shoot-thinning operations (the $\stackrel{\leftarrow}{\mathrm{L}}$ next year's fruiting canes) down support wires.

\section{¿ Yields similar, grades higher}

We found no significant differences between the yields of WRAB DOV and tray-drying for each of 4 consecutive years. The average yield during that 4-year period was 2.7 tons per acre for the WRAB DOV treatment compared with 2.8 tons per acre for the tray-dried treatment. 

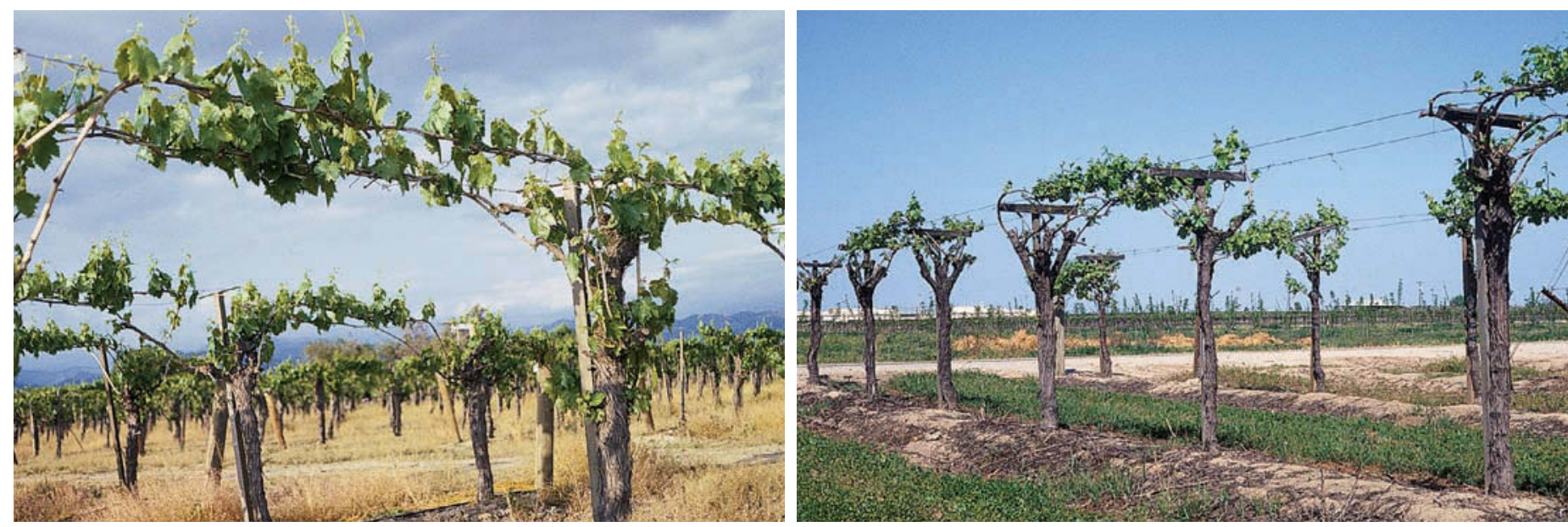

Left, with the traditional method, fruiting canes of 'Thompson Seedless' vines are tied in both directions.

Right, with WRAB DOV, fruiting canes and renewal sections alternate down the vine row.

DOV raisins graded higher than tray-dried raisins when at the same fruit maturity. To compare grades, we picked tray-dried fruit on Aug. 21, 2003, and spread it on paper trays. That same day WRAB DOV vines were summerpruned to initiate drying on the vine. Fruit maturity was measured prior to harvest by collecting 150 berries from each treatment, juicing and then measuring soluble solids in degrees Brix ( ${ }^{\circ}$ Brix) with a refractometer. Raisin quality was determined as percentages at " $B$ or better" (BorB) grade, "substandard" grade (sstd.) and mold (mold). Raisin samples were submitted to the U.S. Department of Agriculture's Agricultural Marketing Service in Fresno for testing. The raisin grades were $63 \% \mathrm{~B}$ or better for WRAB DOV raisins and $36 \% \mathrm{~B}$ or better for tray-dried, a $43 \%$ improvement in grade (table 1).

Shoot thinning of WRAB DOV vines separated the fruiting and renewal areas, reduced shoot congestion

TABLE 1. Quality of WRAB DOV raisins compared
with other methods at same fruit maturity,
summer pruning and tray harvest (8/21/2003)

and facilitated summer pruning. Shoot thinning also enhanced the development of the flower cluster primordia of retained shoots as reflected in the increase in cane fruitfulness the following year (table 2).

The cluster begins as a flower cluster primordia that forms in the bud during the preceding season. This process begins in April and continues through the summer. The early season, beginning about bloom, is a crucial period that determines whether tissue differentiates into flower clusters or into tendrils. Climate, along with the carbohydrate nutrition of the bud, plays an important role. Seasonal variation in vine fruitfulness can usually be attributed to climate conditions in May of the previous year. It can also be attributed to cultural practices during the previous year that affected light and temperature within the canopy and carbohydrate flux in the vine (Williams 2000).

In our research, shoot thinning increased fruitfulness in years when climatic conditions were less than ideal for flower cluster differentiation. We believe that the increased cane fruitfulness that resulted from shoot thinning was the effect of improved carbohydrate nutrition in the retained shoots.

Shoot positioning did not affect cane fruitfulness. However, the shoot positioning placed fruit- ing canes out of harm's way so that the skirt of the canopy could be hedged higher prior to summer pruning. This positioning facilitated winter pruning and tying.

\section{Trellis expansion}

Raisins will not dry on trays unless they are fully exposed to sunlight, and this puts serious constraints on the trellis design and vineyard layout. A wide trellis or narrow row-spacing results in shading of the terrace on which fruit is placed on trays to dry. To increase yields, raisin trellises have gotten a little larger over the years, but not much. Research at KREC has demonstrated that raisin yields will improve $15 \%$ to $20 \%$ with a 7 -foot vertical trellis compared with a 6-foot vertical trellis (Kasimatis 1976). In addition, a small cross-arm (18 to 24 inches) can also improve yields and fruit maturity. But, if the trellis size is increased much more than that and row middles become shaded, the raisins will not dry. Because of trellis limitations imposed by tray-drying, raisin growers have not been able to capitalize on new trellis and canopy management systems. With DOV production, they now can.

In 2002, we began evaluating the effect of different trellises (vertical and " $\mathrm{T}$ " trellises) on 'Thompson Seedless' WRAB DOV raisin production. The trial was located at KREC in a 2.5-acre block of mature 'Thompson Seedless'. The vineyard block was originally trellised with 7-foot stakes and 1.5-foot crossarms with two support wires, but was retrellised to accommodate this experiment. The experiment was designed as 


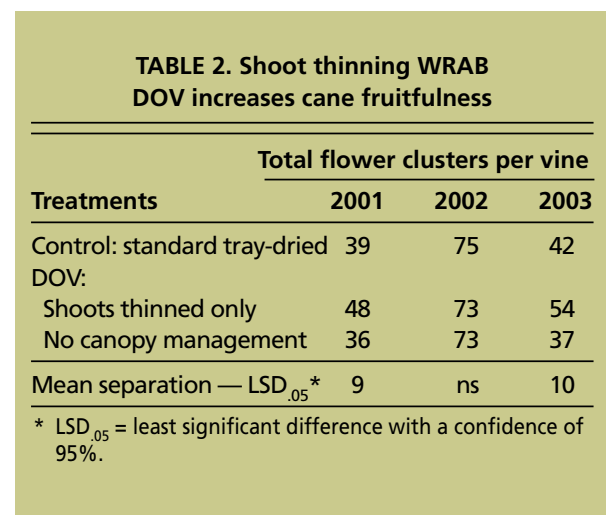

a completely randomized block with six blocks (replications) and five treatments and using 40 vine plots. Five vines per plot were used for data collection.

All trellises utilized 7-foot stakes. Trellis treatments were: (1) vertical, one wire on top; (2) vertical, two wires (top and 14 inches below); (3) 1.5-foot crossarm and two wires; (4) 3-foot cross-arm and three wires; and (5) 4-foot cross-arm and four wires.

Vines for all treatments were pruned to five fruiting canes per vine. Canes were tied using the WRAB DOV system. Shoots were thinned and positioned in the spring. Summer pruning occurred in mid-August. Head fruit was harvested and hung on foliage wires 7 days after summer pruning. Raisins were hand-harvested and weighed, and a subsample was collected for moisture and raisin quality measurements. Raisin yield was adjusted to $14 \%$ moisture based on the moisture content of raisin samples.

Raisin yield dramatically increased with the width of the cross-arm, and the results for 2002 and 2003 were similar. In 2003, the 1.5-foot, 3-foot and 4-foot cross-arms increased yield by $27 \%, 38 \%$ and $73 \%$, respectively, compared with the vertical trellis. The vertical trellis (no cross-arm) was the least productive. The width of the cross-arm had no significant effect on berry weight, soluble solids or raisin quality. Raisin moisture was

TABLE 3. WRAB DOV yields increased by expanding width of trellis (summer pruned, 8/13/03; harvested, 9/26/03)

\begin{tabular}{|c|c|c|c|c|c|}
\hline Trellis treatment & $\begin{array}{c}\text { Berry } \\
\text { weight } \\
(8 / 13 / 03)\end{array}$ & $\begin{array}{l}\text { Soluble } \\
\text { solids } \\
(8 / 13 / 03)\end{array}$ & $\begin{array}{c}\text { Raisin } \\
\text { moisture } \\
(9 / 26 / 03)\end{array}$ & $\begin{array}{l}\text { Raisin } \\
\text { quality }\end{array}$ & $\begin{array}{l}\text { Raisin } \\
\text { yield* }\end{array}$ \\
\hline & $g$ & ${ }^{\circ}$ Brix & $\%$ & $\%$ BorB & tons/acre \\
\hline Vertical \& 1 wire & 1.9 & 17.2 & 14.8 & 46 & 1.96 \\
\hline Vertical \& 2 wires & 1.8 & 17.6 & 14.4 & 40 & 2.06 \\
\hline $18 "$ cross arm \& 2 wires & 1.9 & 17.7 & 15.0 & 57 & 2.54 \\
\hline $36 "$ cross arm \& 3 wires & 2.0 & 17.5 & 14.3 & 49 & 2.76 \\
\hline $48 "$ cross arm \& 4 wires & 1.9 & 17.7 & 14.1 & 55 & 3.46 \\
\hline Mean separation $-\operatorname{LSD}_{.05} \dagger$ & ns & ns & ns & ns & 0.44 \\
\hline
\end{tabular}

similar for all cross-arm widths (table 3). A yield increase with no lowering of fruit maturity indicates that the wider trellises increased the vine's capacity for production.

\section{Harvesting costs and methods}

WRAB DOV harvest costs were calculated for 2- and 3-ton-per-acre vineyards. This typifies the range in raisin yield across the growing region (table 4). Harvest costs for WRAB DOV are fixed on a per-acre basis; therefore, increasing yield proportionately decreases the harvest cost per ton. Tray-drying costs are fixed on a per-ton basis. For cost comparison, the harvest cost for tray-drying raisins is about $\$ 300$ per ton; whereas, the WRAB DOV harvest cost per ton is $\$ 187.50$ for a 2-ton-per- acre vineyard and \$125 for a 3-ton-peracre vineyard.

WRAB DOV production costs include shoot thinning and positioning to separate the fruiting and renewal sections, summer pruning, head fruit removal, machine harvest and trellis repair. The cost of summer pruning and head fruit removal varies considerably between vineyards. Summer pruning costs vary with vineyard age, vigor and vine architecture, and with how well the fruiting and renewal vine sections were separated by shoot thinning. WRAB DOV growers do not have the option of delaying summer pruning beyond late August if they are to successfully dry the raisins on the vine. Vines must be summer pruned no later than Aug. 20 in order to successfully dry raisins to $16 \%$ moisture or below (USDA moisture requirement). It takes about 6 weeks for raisins to dry to $16 \%$ moisture when vines are summer pruned in mid-August. The drying season is essentially over by mid-October.

It is important that green fruit (head fruit) be removed prior to mechanical harvest, which is a major expense. Head fruit is found behind summer-pruned canes, on spurs or on canes that were missed during the summer pruning operation. Head fruit should be harvested within 1 to 10 days of summer pruning and placed on trellis wires to dry. If head fruit is to dry on the vine successfully, it must be placed on the wire no later than Aug. 20. 


\section{We found no significant differences between yields of dried-on-vine and tray-dried raisins for each of 4 consecutive years.}

raisins with a variety of canopy shaker wine-grape harvesters. Our harvest cost is based on the use of a contract wine-grape harvester. Contract harvesting varies depending on location and acreage. Harvester costs would be much lower for growers who own machines.

Raisins are machine harvested much more easily and faster than wine grapes. The dry capstems of the raisins are easily detached from the rachis. DOV raisins harvest predominantly as individual raisins rather than as clusters. After rainfall, however, the capstems rehydrate and mechanical harvest is more difficult. Typically, the harvesting ground speed is about 3 miles per hour ( $\mathrm{mph}$ ) in the morning and $4 \mathrm{mph}$ later in the day. Picking head and fan rotations per minute (rpm) are increased as the day goes on, and both should be evaluated every few hours and adjusted accordingly. The fans are adjusted to remove leaves and some substandard raisins. The picking head, ground speed and fan are adjusted so that harvest efficiency is maximized while damage to the trellis is kept at a minimum. Mechanically harvested raisins can be delivered directly to the packinghouse without shaking across a screen to remove sand and other debris, as is often required with tray-dried raisins.

Trellis damage caused by the machine will vary depending on age and construction material. Damage is greatest the first year of machine harvesting and then diminishes in subsequent years. We budgeted $\$ 50$ per acre for trellis repair, but we also credited a $\$ 50$ per acre savings in winter pruning cost.

\section{DOV research, outreach continues}

Most of the ongoing DOV research focuses on varietal development. 'Selma Pete' is a high-producing cultivar that matures 2 weeks earlier than 'Thompson Seedless'; consequently, 'Selma Pete' can be summer pruned earlier. 'Selma Pete' also dries on the vine more quickly than other DOV cultivars. These characteristics greatly enhance the probability of successful vine drying.

A 'Selma Pete' vineyard on 'Freedom' rootstock is currently being established at KREC. Row spacing and trellis designs that maximize raisin quality and production will be tested. Mechanizing summer pruning is an additional objective. Vines are bilateral, cordon-trained and cane-pruned in order to facilitate summer pruning by machine. In addition to this project, a trial has been initiated to evaluate the performance of 'Selma Pete' grafted to 'Thompson Seedless' and using WRAB DOV.

We have completed our fourth year of research and development of the system, and have extended new information to the industry through newsletters, news releases, seminars and industry meetings. Numerous field days at KREC and in growers' vineyards have introduced raisin growers to WRAB DOV. Growers are accepting the system as a way of cutting production costs, and they recognize the potential for increasing yield by expanding the trellis. In 2003 , about 30,000 tons of DOV raisins were produced using this method.

W.L. Peacock is Farm Advisor, UC Cooperative Extension, Tulare County, and F.H. Swanson is Director, UC Kearney Research and Extension Center, Parlier. The authors gratefully acknowledge financial support from the California Raisin Marketing Board.

\section{References}

Christensen LP. 2000. Current developments in harvest mechanization and DOV. In: Christensen LP (ed.). Raisin Production Manual. UC DANR Pub 3393. p 252-63.

Christensen LP, Peacock WL. 2000. The raisin drying process. In: Christensen LP (ed.). Raisin Production Manual. UC DANR Pub 3393. p 207-16.

Kasimatis AN. 1976. Increasing growth and yield of 'Thompson Seedless' vines by trellising. Cal Ag 30(5):14-5.

Williams LE. 2000. Bud development and fruitfulness of grapevines. In: Christensen LP (ed.). Raisin Production Manual. UC DANR Pub 3393. p 24-9. 